\title{
Smart Metering: A Better Way To Monitor Consumer Electricity Usage
}

\author{
Maman Ahmad Khan ${ }^{1, *}$, Asma Khatoon ${ }^{1}$, Edidong Bassey ${ }^{2}$, Bilal Amin ${ }^{1}$, Hafiz \\ Hashim Chaudhry ${ }^{3}$ \\ ${ }^{1}$ Electrical and Electronic Engineering, National University of Ireland Galway, \\ Ireland \\ ${ }^{2}$ Department of Accountancy and Finance, National University of Ireland \\ Galway, Ireland \\ ${ }^{3}$ Mechanical Engineering, National University of Ireland Galway, Ireland \\ m.khan7@nuigalway.ie, a.khatoon1@nuigalway.ie,e.bassey2@nuigalway.ie \\ b.amin2@nuigalway.ie, h.hashim1@nuigalway.ie
}

\begin{abstract}
This paper presents the development and implementation of a low-cost smart meter. The smart meter is one of the major components of the distribution network. The proposed low-cost smart meter is compared with already existing smart meters deployed in the market. The comparison metrics involve cost, security, installation, and lifetime. In this study, we have presented the market segment and the beachhead market of the proposed product. The TAM size is calculated for better market analysis by calculating the overall customer size. A complete proposed process flow is explained for cost saving comparison, along with a complete market survey. In this paper, the whole technology and hardware needed for the low-cost smart meter is explained in detail along with the total cost of testing and installation.
\end{abstract}

\section{Keywords}

Business Model, Distribution System Operators(DSO), Low-Cost Smart Meter, Utility Market, Electricity Management System.

\section{Introduction}

The distributed energy resources like; solar panel and wind turbines on low voltage distribution networks, have converted the consumers to prosumers [1]. However, this modernization in power system network brought certain challenges for the distribution system operators, like, the need to maintain the stability of the grid for the proper functioning of the network. Even the distributed system operator has very little real-time data and information of the low voltage side. This brings the need of the smart meters, which replaces the traditional energy meters. The conventional meters use to work as a black box and give energy usage for billing purpose only. With the advent of the smart meters the utility companies now have more control over the network which helps in proper monitoring and control of the system [2]. Along with this, smart meters serve best for saving energy with proper control and monitoring of the house appliances as it provides more detailed information on the electricity usage. With the help of smart meter, the households will have the opportunity to contribute in the national grid of electricity. This can be done very easily by adjusting the energy usage at the peak time of the day and use their heavy loads when the demand is low. This can be done by proper monitoring of the house network with the help of smart meters [3]. 
Using smart meter will help to monitor peak manage demand, which will help in lowering the cost for the consumers. Ireland is relatively a very late country to consume the smart meters. In 2009-10, overall 5000 homes in Ireland were kept on trial and a peak time reduction of $8.8 \%$ was reported [4]. However, after all these benefits of the smart meter, there are some cost and security issues as well for the mass implementation. The benefit for the Ireland consumers will be that the smart meter roll-out will not be supplier led which will give consumers the option to change the electricity supplier even after installation of the smart meter. Although, this brings a huge competition between the utility companies to install a low-cost smart meter which does not increase the cost and billing for consumers. This led the regulators to face a huge task of installing the smart meters with the public agreement over the cost and charges. The Commission for Energy Regulation in Ireland is aiming to install 250,000 smart meters between 2019-2020 with further 50 thousand every year for the next four years till 2024 [5]. Hence, looking at such a big market all the smart meter companies have started to compete for the implementation of their product.

\section{Market Layout}

In this study, we have focused our market segment as private household customers. The study and its implementation will have a significant impact on better monitoring of electricity usage in terms of theft monitoring and optimum need for electricity consumption in every room of the house. It has been observed in the recent past from various studies that due to improper electricity consumption in house hold equipment's, the electricity usage is not properly monitored. Thus smart devices like our proposed smart meter will be required to monitor better consumption of electricity. In this study, we have surveyed the beachhead market. The total size of the market was found to be 2,003,645 [6]. Out of this market size, approximately 1,147552 houses are owner-occupied. Approximately 535,675 houses are at the mortgage and 611,877 houses are owned outright. We have surveyed the end user profile in order to identify the consumption of electricity consuming devices. In this regard, we observed that approximately $72 \%$ of the house owner's age was between 35- 45 years. Among the surveyed end users it was found that approximately $82 \%$ are rural house owners and 59.2\% are urban house owners. The beach head TAM size was calculated in this study. We found a beach head TAM size of 826,237.44 for the owner's age range of 35-45 years. After detailed market analysis and design specifications, we set an optimum amount of our SMART meter to be 250 euros. Based on beach head TAM size the overall price was found to be 206,559,360 euros.

In order to examine the market depth [7], we have surveyed market in order to estimate the customer profile. We found our main investor to be PANDA POWER [8] having a market penetration of $1.5 \%$. Approximately 150,000 customers in Ireland have employed SMART meter manufactured by PANDA POWER. Mostly their customers are based in Dublin. By examining the market penetration depth, we concluded that a large market can be exploited in order to get maximum penetration depth in the market. The flow sheet diagram of the life cycle of ease is shown in figure 1 . 


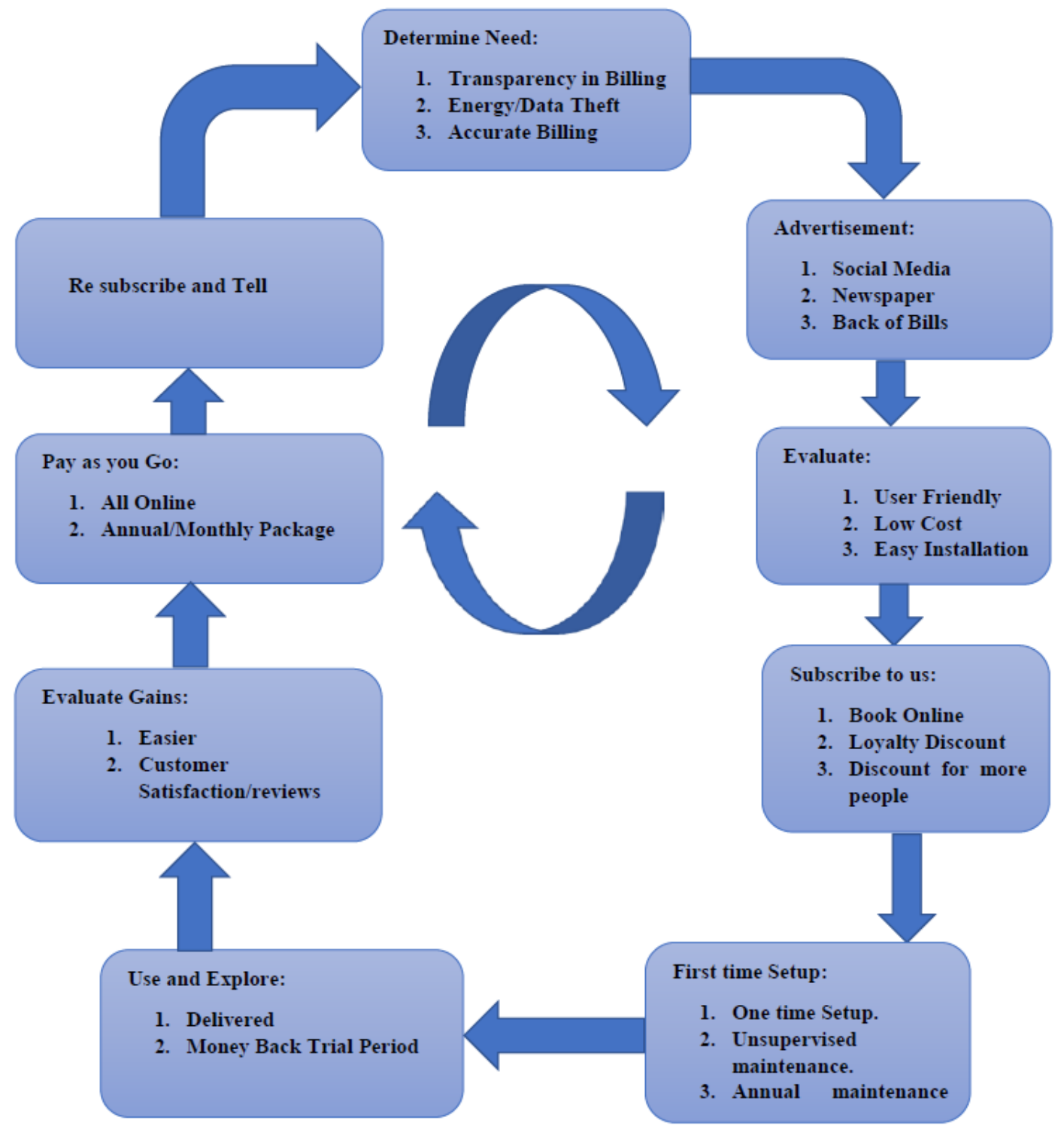

Figure 1. Life Cycle with ease

\section{Product Specification}

To better quantify the device in terms of specifications, we have defined a few highlevel specifications of our device, these are:

1. Monitoring of electricity usage by appliances.

2. Secure and accurate billing information.

3. No electricity theft, user-friendly device.

4. Cost-effective device, easy installation on existing meters.

The high-level specifications of our smart meter ensure monitoring of electricity usage of the appliances that will be using electricity on a continuous basis. In order to monitor billing information a secure and accurate billing information will suffice the cause [9]. In order to avoid electricity theft, we have added special security measures in the device. One of the major high-level specifications of our device is cost-effectiveness and easy installation on existing meters. 


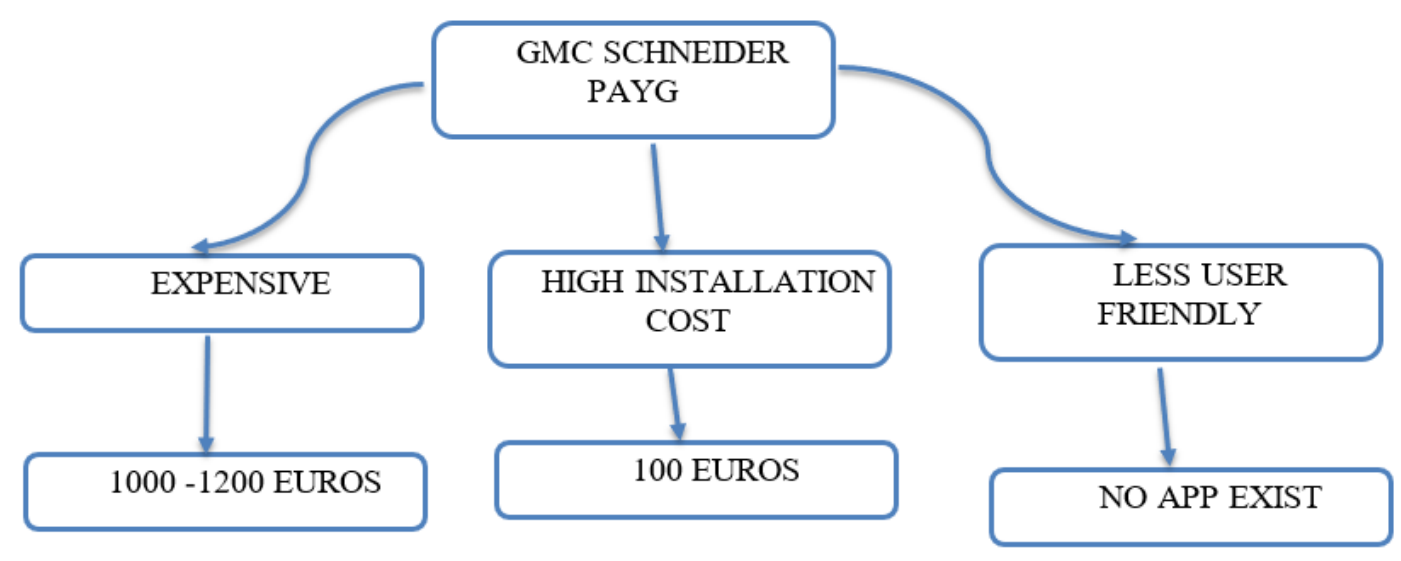

COST 1100 EUROS

Figure 2. Current process flow diagram

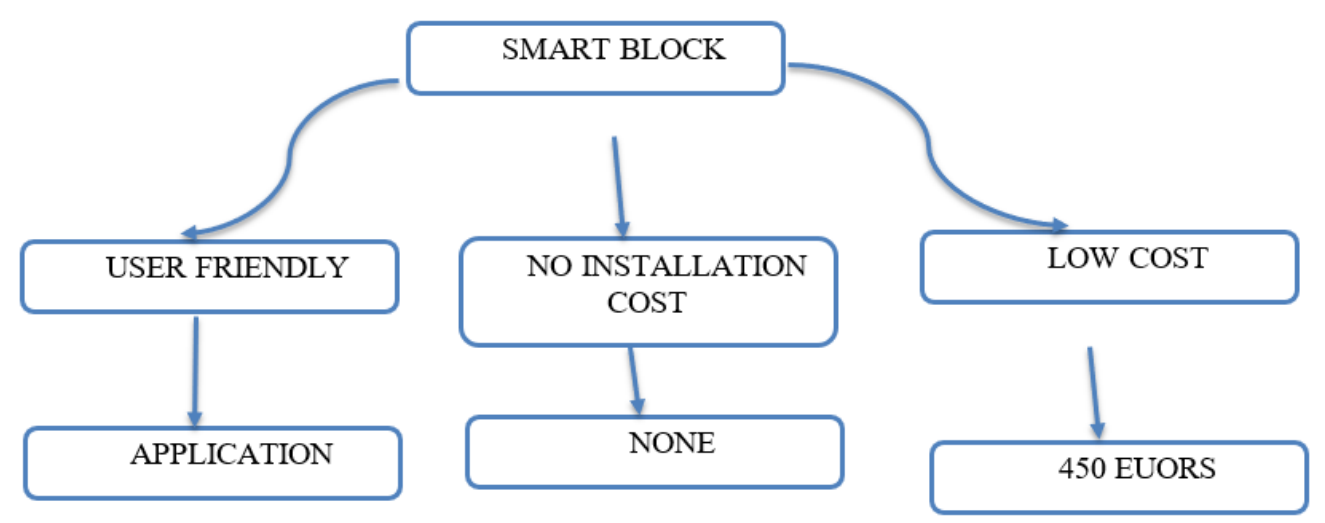

SAVING COST 650 EUROS

Figure 3. Proposed process flow diagram

\section{Disciplined Entrepreneurship Details}

To compare previous and proposed process diagrams, we have presented the data in figure 2 and 3 respectively. It can be deduced from the flow sheet diagrams that the installation of the proposed system will ultimately safe 650 Euros at each customer end. The overall market penetration of all smart meter install companies we surveyed all companies market penetration and found following figures [8]:

1. ELECTRICITY IRELAND $=49.5 \%$

2. BORD GAIS ENERGY $=17.8 \%$

3. SSC AIRTRICITY $=15.36 \%$

4. ENERGIA $=7.9 \%$

5. PREPAY POWER $=5.9 \%$

6. PANDA POWER $=1.5 \%$

7. PI ENERGY $=1.4 \%$ 
Based on a review of market penetration, ELECTRIC IRELAND was found to be the most significant market competitor. The core of our technology is defined in figure 4. It can be well observed from the figure that our technology provides a digital global solution. There is no separate need of $\mathrm{WiFi}$ and display. The processing unit does not involve expensive processors.

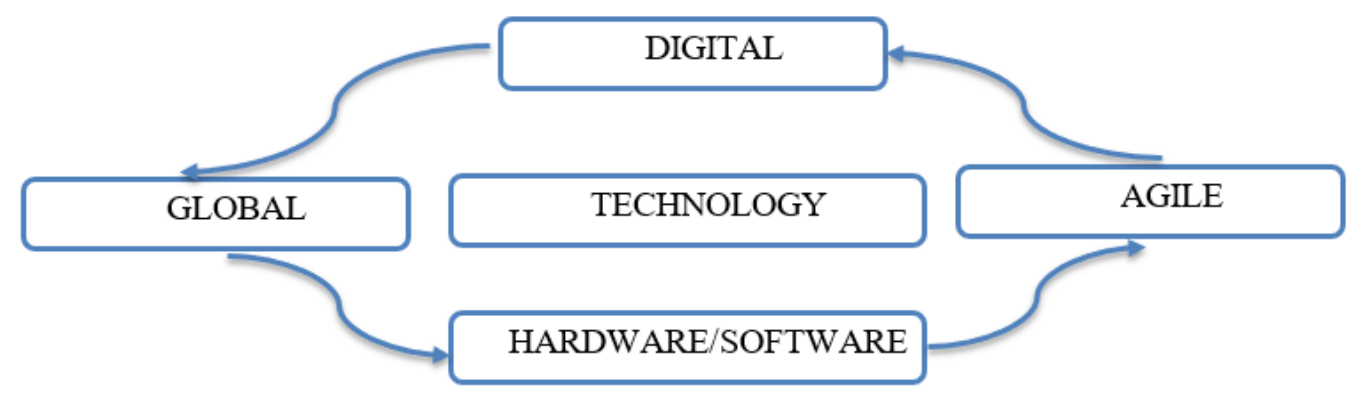

Figure 4. Definition of our Core

\section{Technical Detailing}

The main software system involved in the core of our technology will be GigSILENT Power Factory, PYTHON, PUTTY, PTP4L/PTP daemon [10],[11]. We have analyzed our competitive position in the market compared with our companies. After analysis, we found our proposed system in the high-high region. To find market penetration our two main priorities were low cost, user-friendly and secure and reliability. The PAYG meters have high priority in terms of security and reliability but their cost is high and not user-friendly systems [12]. Contrary to this, GMC and Schneider Electric has low cost and user-friendly systems but they are not the secure and reliable system. In the proposed company setup the technical contact will be the lead developer and financial evaluation will be performed by the finance manager. The marketing officer has designated the charge of chief marketing officer. The validation and testing will be performed by the testing engineer. The CMO will be in charge of the proposal to the board of directors.

The customer acquisition process is mapped in the following way:

1. Technical team contact.

2. Validation and testing.

3. Transformation of product in their model parameters.

4. Financial Evaluation.

5. Market survey (Price and Suitability).

6. Chief Marketing Officer Decision.

7. Proposal to the board of directors.

\begin{tabular}{|c|c|c|c|c|c|}
\hline $\begin{array}{c}\text { Technical } \\
\text { Contact }\end{array}$ & Validation & Finance & $\begin{array}{c}\text { Product } \\
\text { Market } \\
\text { Survey }\end{array}$ & $\begin{array}{c}\text { CMO } \\
\text { Update }\end{array}$ & $\begin{array}{c}\text { Board } \\
\text { Approval }\end{array}$ \\
\hline 2 months & 6 months & 4 months & $\begin{array}{c}1-2 \\
\text { months }\end{array}$ & 1 month & 1 month \\
\hline
\end{tabular}


The electricity monitoring will be carried out in private units as well as at electricity plants [13]. The electricity monitoring education will be given at higher education and school level. The overall flow of electricity monitoring is shown in figure 5.

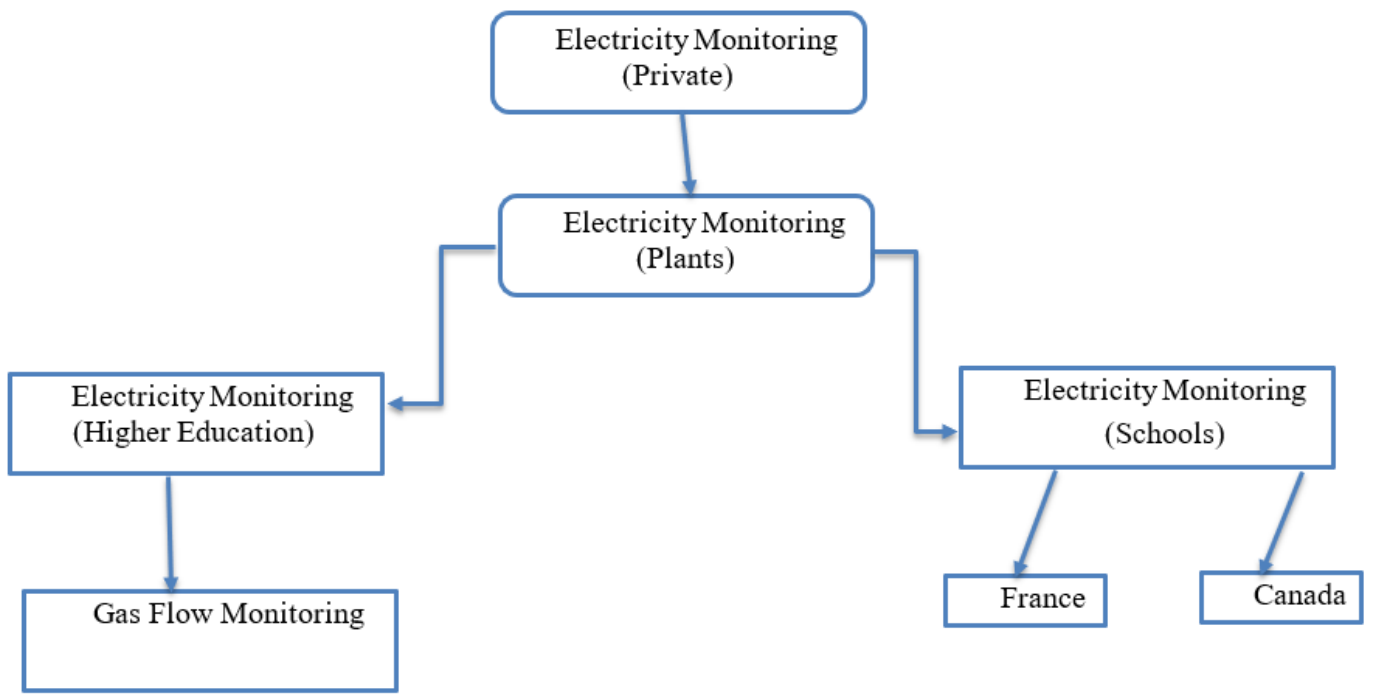

Figure 5. Electricity Management System

We have proposed the pricing framework of our proposed system. In the initial stages, we have the plan to send 50 smart meters free for testing and evaluation purpose. In order to keep things easy for the utility company, we have planned to send the testing engineer for free installation of our equipment. A bulk discount of $11 \%$ will be offered for every 500 hours. Updates on subscription of the latest offers will be given to customers. The short-term goal is to purchase a software and supply to Panda and Panda supplies to households. In the long term the purchase and development of software will be planned and will be supplied to the electric power company and finally, the electric power supplies the software to households [14]. Our business model is defined with the following major priorities:

1. Online

2. Subscription

3. Future Updates

We have allocated cost to our software and hardware components. The cost designated as follows :

\section{Software}

- $\quad$ Putty $=50$ euros

- Application Development Update $=40$ euros

\section{Hardware}

- $\quad$ Rasperry-Pi $=100$ euros

- Sensors $=40$ euros

- Adopter $=20$ euros

The key assumptions of our proposed system are: 
1. Proper monitoring of power consumption.

2. Real-time monitoring of distribution network.

3. Reduce the complexity of distribution network.

4. Induce transparency in controlling and protecting measurement devices.

5. Rapid fault detection at user-end

6. Government future policy.

7. Governmental policy of power loss control and protection of citizens.

8. Unviability of detailed information of power consumption.

9. Control over user profile.

Hardware Update (Raspberry Pi = Beagle Box)

Improved Software (Less Bugs on User-End)

Compact Licensed Block

\section{Discussion}

Decarbonization of electricity results in the introduction of renewable energy resources. These resources are integrated into the power grid on the distribution network. This connection of renewable resources, like, solar panel and wind turbine leads to the bidirectional flow of power. However, this modification in the network leads to the need of better monitoring instruments in a much complex network. Hence, in this era of the smart grid, the conventional energy meter does not meet the demands of the network. This uncalled problem gives an opportunity to electronic companies to exploit the market and to develop and propose smart meters that can be employed at the consumer end. After considering current smart meters deployed in the market, we proposed a low-cost smart meter which plays a significant role in cutting down the cost for the utility companies. Since the government has announced the installation of smart meters to be mandatory thus cutting down the cost will be beneficial for both the distributed network and the end customers. For a country like Ireland where the consumer can change the power companies even after the installation of the smart meter, it has become a need for them to buy a cheap smart meter. A complete 24 steps of disciplined Entrepreneurship for starting a company which design smart meter has been justified in the paper with full detail.

\section{Future Directions}

After consideration of all needs and norms for the company, the future direction is to buy licensed software which will help in developing the low-cost hardware's function. After designing and testing of the instrument, an attempt will be made to demonstrate the working of this smart meter in different utility companies. Our main goal will be to start with PANDA POWER, as they are currently dealing in Dublin, so it will be easy to focus our team in a small area to give our company a good start. After a good advertisement of our product, we will also try to give our customer an option of trying different models which can be a tradeoff between cost and functionalities. 


\section{References}

[1] K. Balamurugan, D. Srinivasan, and T. Reindl, "Impact of Distributed Generation on Power Distribution Systems," Energy Procedia, vol. 25, pp. 93-100, 2012.

[2] G. Dudek, A. Gawlak, M. Kornatka, and J. Szkutnik, Analysis of Smart Meter Data for Electricity Consumers.

[3] D. Scholz and F. Müsgens, How to improve Standard Load Profiles: Updating, Regionalization and Smart Meter Data.

[4] Mark Whelan and Former Head of Communications \& Events, "Smart electricity meters are coming to Ireland | bonkers.ie." [Online]. Available: https://www.bonkers.ie/blog/gas-electricity/smart-electricity-meters-arecoming-to-ireland/. [Accessed: 12-Nov-2018].

[5] S. Chren, B. Rossi, and T. Pitner, Smart Grids Deployments within EU Projects: The Role of Smart Meters. 2016.

[6] "CRU Publishes Results of Energy Consumer Survey - Commission for Regulation of Utilities." [Online]. Available: https://www.cru.ie/2018/04/18/cru-publishes-results-of-energy-consumersurvey/. [Accessed: 13-Nov-2018].

[7] "A Commission for Regulation of Utilities Smart Metering Cost-Benefit Analysis." Dublin, Ireland, 2017

[8] "Panda Power - Ireland's customer-focused energy provider." [Online]. Available: https://www.pandapower.ie/. [Accessed: 13-Nov-2018].

[9] B. Romer, "The Neverending Story of the Smart Metering Technology-What needs to be done for a Happy End?"

[10] I. Kim, R. Regassa, and R. G. Harley, The Modeling of Distribution Feeders Enhanced by Distributed Generation in DIgSILENT.

[11] "Precision Time Protocol daemon / [Ptpd-devel] ptpd vs ptp4l." [Online]. Available: https://sourceforge.net/p/ptpd/mailman/message/30816543/. [Accessed: 13-Nov-2018].

[12] "Pay As You Go Meter." [Online]. Available: https://www.esbnetworks.ie/existing-connection/meters-readings/pay-asyou-go-meter. [Accessed: 13-Nov-2018].

[13] N. A. Kulatunga, S. Navaratne, J. Dole, C. Liyanagedera, and T. Martin, "Hardware development for Smart Meter based innovations," in 2012 IEEE Innovative Smart Grid Technologies - Asia, ISGT Asia 2012, 2012.

[14] N. S. Živi, O. Ur-Rehman, C. Ruland, and S. Member, Evolution of Smart Metering Systems. 